\title{
Tissue response to aqueous drainage in a functioning Molteno implant
}

\author{
K U LOEFFLER' ${ }^{1}$ AND J L JAY ${ }^{2}$ \\ From the Departments of 'Pathology and ${ }^{2}$ Ophthalmology, The University of Glasgow
}

SUMmary The tissue reaction to a functioning Molteno implant has been studied by light microscopy and by scanning and transmission electron microscopy. The material was obtained from an aphakic 83-year-old human eye which required enucleation because of intractable bullous keratopathy, despite well controlled intraocular pressure. The tissue response around the silicone rubber tube was that of simple fibroblastic activity. Around the implant, however, there was fibrous tissue in which necrotic cell debris was prominent. No significant inflammation was observed in this tissue, but the choroid beneath the implant showed a focal inflammatory cell infiltrate. The morphology suggests that the tissue around all surfaces of the implant $\left(450 \mathrm{~mm}^{2}\right)$ is exposed to aqueous, which seems to have a toxic effect on the encapsulating connective tissue. The changes seen in the tissue exposed to draining aqueous are similar to those described in experimental studies of the effect of aqueous on cell growth in tissue culture.

Various surgical drainage procedures using the implantation of foreign material have been developed in the treatment of glaucoma. In 1960 Ellis' reviewed the history of attempts to provide a suitable drainage fistula, and the material used to maintain a channel out of the eye includes horsehair, which was glued to the cheek over silk, various metals, gelatin, cartilage setons, and finally plastic materials. In recent years plastic materials have been modified and improved to obtain encouraging results even in previously unfavourable cases. ${ }^{2-5}$

In 1969 Molteno $^{67}$ introduced a new plastic implant for the management of neovascular glaucoma, and after several modifications ${ }^{89}$ it has been accepted as a useful tool for severe cases of uncontrolled intraocular pressure..$^{9-13}$

To our knowledge no histological description on human material has yet been available for the study of the drainage area and the effect of aqueous on the tissue surrounding a functioning Molteno implant. In the case reported here we document the histopathological findings in an eye with a successful Molteno long tube implant.

Correspondence to Dr J L Jay, Tennent Institute of Ophthalmology, Western Infirmary, Church Street, Glasgow G11 6NT.

\section{Case report}

A 74-year-old woman developed severe acute angle closure glaucoma in both eyes in 1975 which was successfully treated by peripheral iridectomies. Thereafter the intraocular pressure remained between 16 and $20 \mathrm{mmHg}$ without supplementary therapy. In 1979 intracapsular cataract extraction was performed in the right eye. The postoperative course was complicated by a transient rise in intraocular pressure to $60 \mathrm{mmHg}$, and aphakic bullous keratopathy persisted despite normal intraocular pressure without therapy. The corneal condition became painful, and in 1981 an $8.0 \mathrm{~mm}$ diameter penetrating keratoplasty with anterior vitrectomy was performed combined with trabeculectomy at the 8 o'clock meridian. The graft remained clear, allowing visual acuity of $6 / 18$, but the intraocular pressure once again proved difficult to control. Therefore a trabeculectomy together with scleral pillar inclusion was performed at the 6 o'clock meridian two months later.

This operation and subsequent cyclocryotherapy in the upper half of the globe were not successful, and the intraocular pressure continued to vary between 12 and $30 \mathrm{mmHg}$ with gradual failure of vision to 


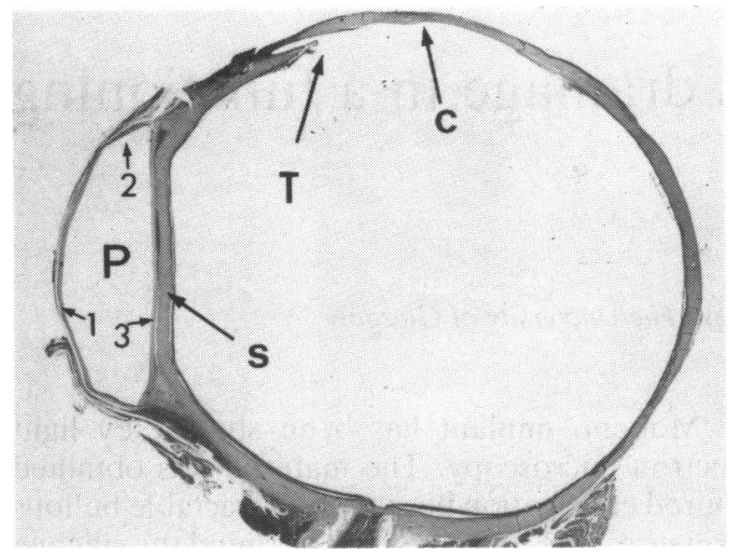

Fig. 1 Paraffin section of enucleated globe (Hand E). P: plate cavity with outer wall (1), lateral wall (2), and inner wall (3), S: underlying sclera; T: opening of tube tunnel into the globe, $\mathrm{C}$; cornea.

no perception of light in 1983 . The corneal graft developed oedema during 1984, and uncontrolled intraocular pressure up to $45 \mathrm{mmHg}$ produced distressing frontal pain.

In June 1985 a single plate Molteno long tube implant was placed on the equatorial sclera under Tenon's fascia in the superonasal quadrant and fixed in position by two 8.0 virgin silk sutures at its anterior edge. The proximal part of the tube was buried under a partial thickness scleral flap and its free end tucked temporarily under the medial rectus muscle. Eight weeks later the conjunctiva was reopened and the free end of the tube was repositioned under a scleral flap contiguous with the previous flap. These flaps therefore formed a continuous intrascleral tunnel for the tube, which was inserted in the eye via a stab incision under the limbal end of the second flap. Postoperative medication consisted of betamethasone drops and chloramphenicol drops four times daily and atropine drops twice daily for one month. The intraocular pressure remained approximately $22 \mathrm{mmHg}$, and the patient had no further frontal pain.

Eight months later, however, painful bullous keratopathy developed without increase in intraocular pressure, and the eye was enucleated. Immediately after enucleation the globe was fixed in cacodylate-buffered glutaraldehyde $(2 \%)$.

\section{MACROSCOPIC EXAMINATION}

On external examination the plate was located in the superonasal equatorial region of the globe within episcleral tissue. It measured $13 \mathrm{~mm}$ in diameter with a calculated total surrounding surface area of approximately $450 \mathrm{~mm}^{2}$. As the plate was expected to be too hard for sectioning, it was removed from its smooth walled episcleral cavity after cutting it free from the two scleral fixation sutures. The softer drainage tube into the anterior chamber was left in situ. There were no adhesions between the plate material and the surrounding fibrous tissue. The cavity itself formed an oval space (Fig. 1) corresponding to the slit-lamp observation of a deep drainage bleb around the plate. Apart from glaucomatous atrophy the ocular tissues showed no significant abnormality. The eye was then sectioned in an oblique plane to display the pupil, the optic nerve, and the central part of the bleb cavity for paraffin histology.

\section{LIGHT MICROSCOPIC EXAMINATION}

Serial sections for light microscopy were stained with haematoxylin-eosin, and additional special stains periodic acid Schiff (PAS), alcian blue/PAS, PAS after diastase, Prussian blue, reticulin, Masson trichrome, picro-Mallory V, Bodian, Loyez - were performed on selected levels.

Microscopic examination confirmed the features of longstanding bullous keratopathy with formation of vesicles beneath the corneal epithelium and partial loss of Bowman's layer. Peripheral corneal vascularisation was also present. The corneal transplant could be identified by stromal scarring at the host-graft junction with small gaps in Descemet's membrane at this site, allowing the formation of a thin retrocorneal membrane localised to the area of the wound. The inferonasal trabeculectomy was demonstrated histologically as half-thickness sclera lined internally by fibrotic remnants of ciliary body. Elsewhere the angle of the anterior chamber was closed by iridocorneal adhesion, and the residual trabecular meshwork was hyalinised and degenerate.

At the penetration site of the Molteno tube into the anterior chamber there was some distortion of Descemet's membrane and adjacent atrophic iris tissue, but no significant inflammatory reaction was found (Fig. 2a, b). The intrascleral tunnel for the tube was lined by a layer of spindle-shaped cells which extended up to the opening into the plate. The cavity of the Molteno plate was surrounded by a rim of fibrous tissue (Fig. 2c, d), which was distinguished from scleral collagen by its looser architecture and the presence of abundant PAS-positive granules (Fig. 2e, f, g). These granules were not present elsewhere in the episclera of this eye or in a corresponding episcleral area of an eye enucleated for an intraocular melanoma. The inner wall, the lateral wall, and the outer wall of the plate cavity, however, were of identical morphological appearance. Unlike the lining of the tube tunnel there was no cellular 

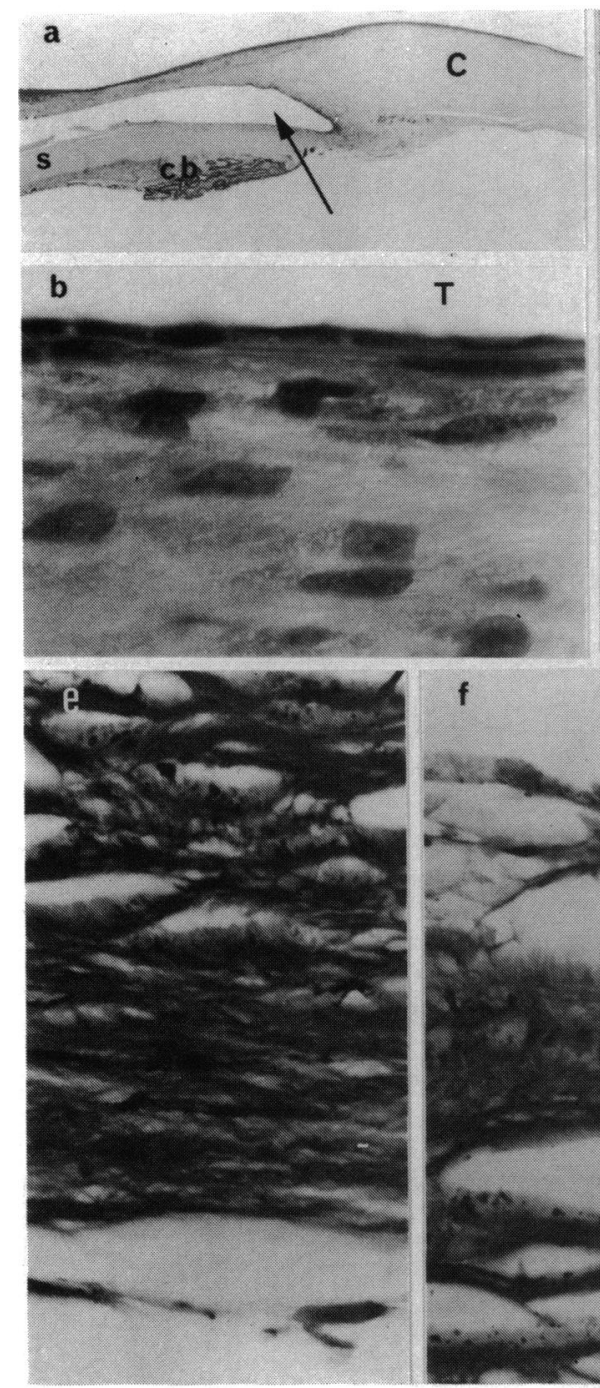

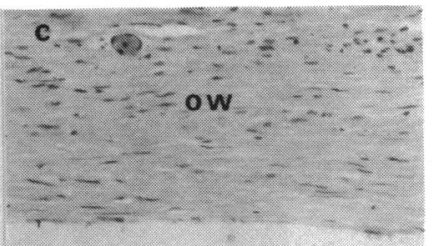

C

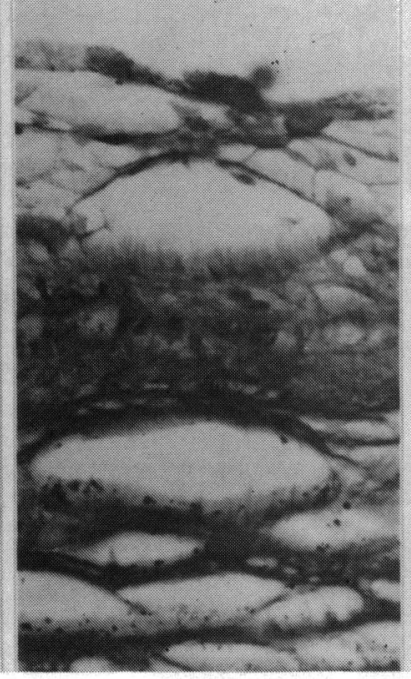

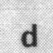

C

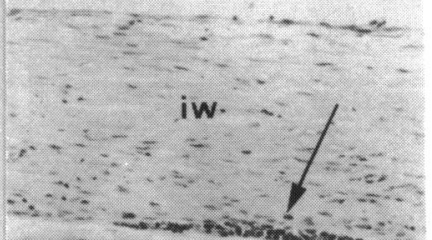

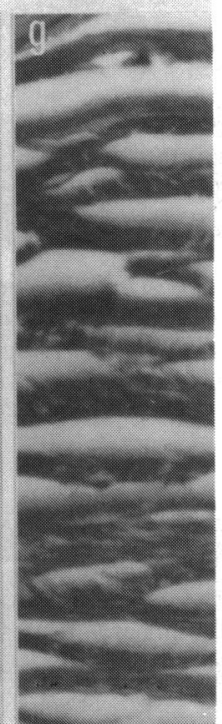

Fig. 2 Light microscopic appearance of tissues around implant. (a) Tube tunnel (arrow) near perforation into anterior chamber (H and E); note angle closure. C: Cornea, cb: ciliary body, s: sclera. (b) Detail of spindle cells lining tube tunnel $(\mathrm{T})$ ( H and $E)$; note absence of inflammatory cells. (c) Outer wall (ow) of plate cavity (C) (H and E); note absence of surface differentiation. (d) Inner wall (iw) of plate cavity (C) (H and $E)$; note absence of surface differentiation and inflammatory cell infiltrate (arrow) at border with intrinsic scleral collagen. (e) Detail of outer wall (alcian blue/PAS); compare with tube lining cells in (b); note numerous granules between the collagen lamallae. (f) Detail of inner wall (alcian bluel $P A S)$; note similar granules as in outer wall. (g) Sclera shown for comparison (alcian blue/PAS); note absence of granules and more regular architecture of collagen lamellae. surface differentiation in the plate cavity, the latter being simply lined by collagen and fibroblasts (Fig, 2c, d).

Only a few inflammatory cells and macrophages were seen predominantly within the inner wall and some cellular debris was also present. Evidence of abnormal fibroblastic proliferation was not seen. Capillaries were more numerous over the implant than within the episclera elsewhere, but there were no features of oedema, and there was only a very mild focal plasmacytic response around some of these vessels.

Inflammation, in the form of a giant cell granulomatous reaction, was much more prominent around the intrascleral suture material, and a focal inflammatory cell infiltrate was found between the sclera and the inner wall of the plate cavity (Fig. 3a, c). There was also focal inflammation within the choroid beneath the Molteno implant (Fig. 3a), but the remainder of the choroid was normal. The retinal pigment epithelium overlaying this area of focal choroiditis showed an increased number of drusen (Fig. 3b) in comparison with the rest of the eye. The retina showed advanced glaucomatous atrophy with loss of ganglion cells and nerve fibres and a deeply cupped optic disc. A transverse section across the optic nerve revealed marked thickening of the pial septa and almost complete axonal loss. 

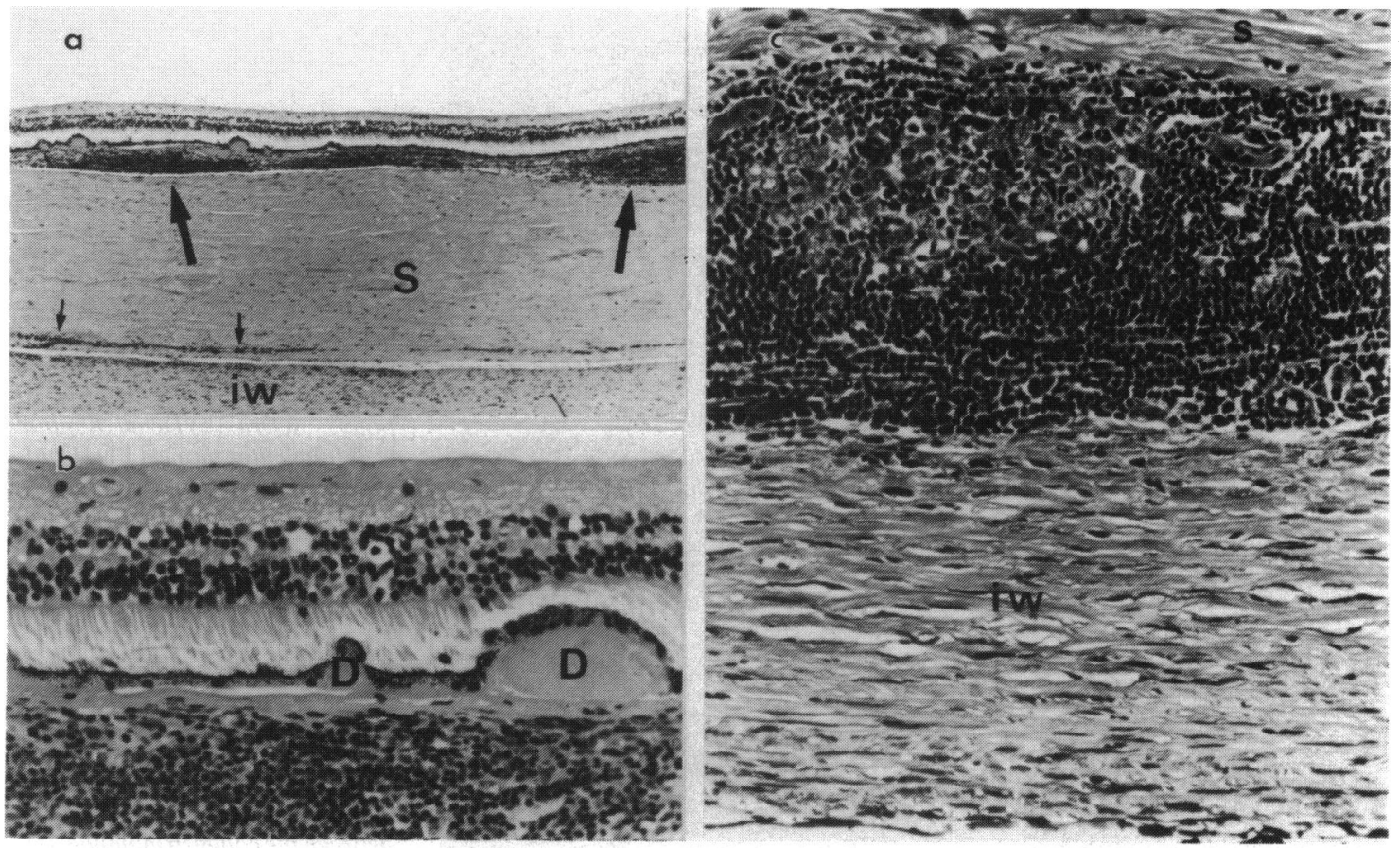

Fig. 3 (a) Low-power section across coats of the eye beneath plate cavity showing focal inflammatory cell infiltrate in the choroid (arrow) and beneath the inner wall (iw) of the cavity ( $\mathrm{H}$ and $\mathrm{E}$ ); intervening sclera (s) shows no significant abnormality. (b) Drusen formation (D) of RPE overlying cellular infiltrate in choroid (H and E). (c) Granulomatous inflammatory cell infiltrate between sclera (s) and inner wall (iw) (H and $E)$.
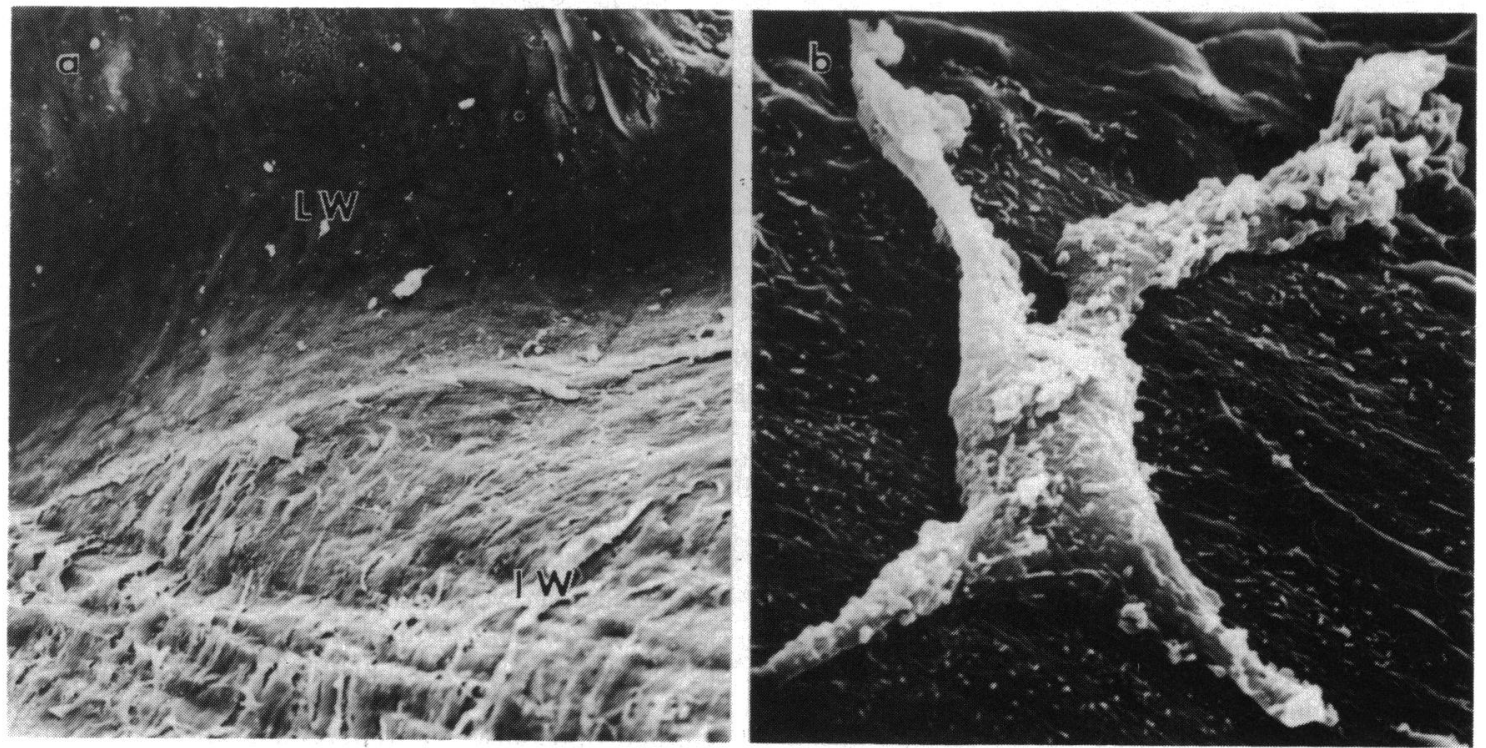

Fig. 4 (a) Inner wall (IW) and lateral wall (LW) of plate cavity showing almost complete absence of cell covering. SEM. (b) Isolated cell on surface of inner wall of plate cavity. SEM. 

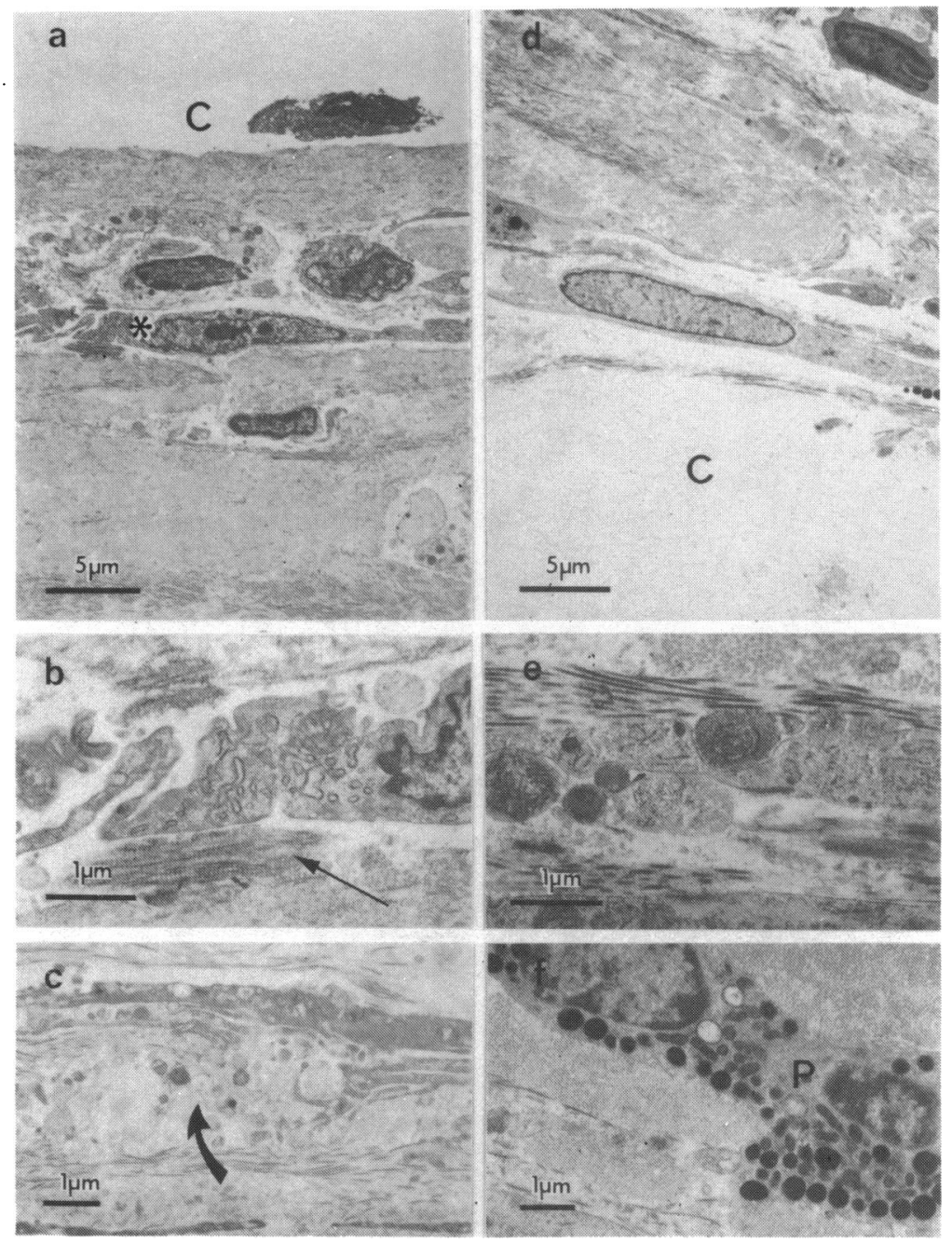

Fig. 5 (a)Inner wall of plate cavity (TEM). C: cavity; note absence of surface differentiation. *: fibroblast shown in (b). (b) Detail of (a) showing active fibroblast and adjacent collagen (arrow) (TEM). (c) Cell process of fibroblast (TEM); note numerous extracellular granules (arrow). (d) Outer wall of plate cavity (TEM). $\mathrm{C}$ : cavity; note absence of surface differentiation similar to (a). (e) Cell processes and loose collagen bundles in outer wall (TEM). (f) One of the few polymorphonuclear leucocytes $(\mathrm{P})$ found between collagen fibres in the outer wall.
ELECTRON MICROSCOPIC INVESTIGATION

Tissue from the roof and the adjacent lateral and inner wall of the plate cavity was taken from the calottes and processed routinely for scanning electron microscopy (SEM). Several blocks from the same area were also processed in a conventional fashion for transmission electron microscopy (TEM) and embedded in Araldite. Ultrathin sections were cut with an LKB Ultrotome III, stained with uranyl acetate and lead citrate, and examined with a Philips 301 transmission electron microscope. Material from the tube tunnel was not studied by electron microscopy to preserve the entirety of the specimen for light microscopic sections.

Ultrastructural examination of the connective tissue around the plate cavity revealed similar features in both the outer and inner wall. By SEM the outer and lateral wall appeared slightly smoother than the inner wall but no significant difference could be noted (Fig. 4a). A few large cells were present on each side facing the plate but there was no continuous cellular layer lining the cavity (Fig. 4b). TEM showed the wall to be composed mainly of collagen which was of normal appearance but not as regularly arranged as in the sclera (Figs. 5 and 6). Some fibroblasts showed features of activation such as a prominent rough endoplasmic reticulum and a dilated Golgi apparatus (Fig. 5b). Inflammatory cells, for example, polymorphonuclear leucocytes, were seen only occasionally (Fig. 5f). There was, however, evidence of cell death, and extracellular granules and other cellular debris were found between the collagen 
Fig. 6 (a)Inner wall of plate cavity showing irregular collagen arrangement and some cellular debris (arrow) but also well preserved fibroblasts (f). TEM.

(b) Outer wall of plate cavity where cell death $\left(^{*}\right)$ and cellular debris are more prominent (TEM); note loose architecture of collagen. (c)

Episcleral vessel at outer aspect of outer wall showing gaps (arrow) between endothelial cells. TEM. (d) Higher magnification of an intercellulargap. TEM.
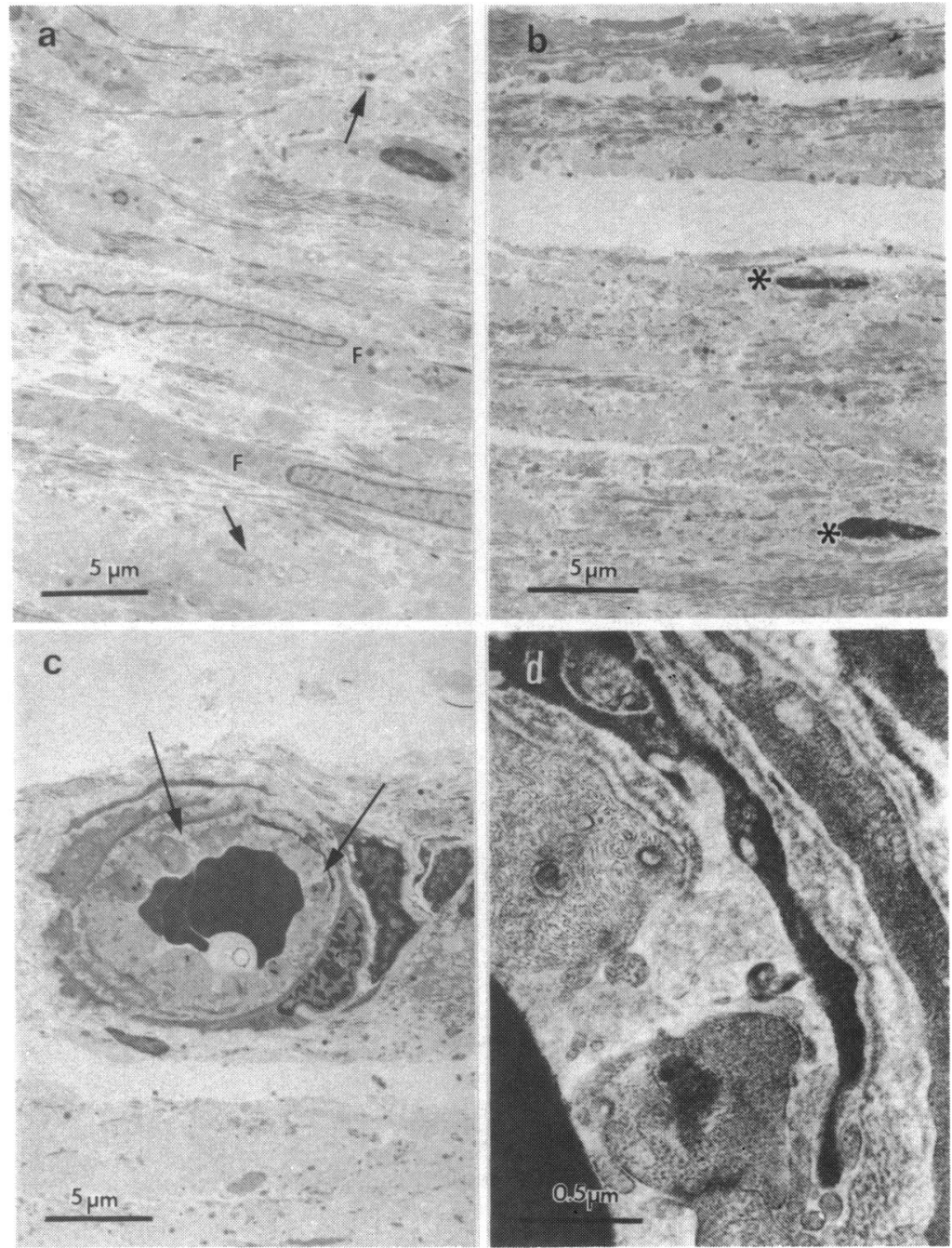

lamellae (Fig. 6a, b). As observed by SEM there was no continuous cell layer lining the inner aspects of either outer or inner wall: the surface was formed predominantly by collagen fibres and only sparsely interspersed cells. Episcleral vessels over the implant showed prominent intercellular gaps within the endothelium. (Fig, 6c, d).

\section{Discussion}

The two major problems of this type of glaucoma surgery are uncontrolled hypotonia and late obstruction of the drainage fistula by excessive scarring due to fibrovascular proliferation.
The Molteno long tube implant in this case was inserted in a two-stage procedure as recommended by Molteno ${ }^{9}$ to avoid an undesired rapid fall in intraocular pressure. In subsequent cases we have devised a modification which allows a satisfactory one-stage operation. The location of the plate and insertion of the tube is now carried out as a single operation using an absorbable ligature of 8.0 gauge polyglycolic acid suture to provide temporary restriction of aqueous drainage along the tube. This seems to allow adequate initial drainage without hypotonia.

To avoid fibroblastic proliferation with subsequent occlusion of the drainage bleb, Molteno has recommended a more posterior location of the plate and 
additional heavy antifibrosis and immunosuppressive therapy. ${ }^{8}$ This medication can show significant side effects, ${ }^{10}{ }^{12}$ and we have not used such a regimen. It appears therefore of great interest that, despite the absence of such drugs in the present case, the bleb wall did not appear abnormally inflamed or thickened.

Aqueous has been reported to inhibit the initiation of growth of fibroblasts. ${ }^{1+16}$ This might explain the features of degeneration and cell death seen in the tissue around the implant. It would also support the concept that antifibrosis therapy is not necessarily needed to prevent undesired scarring of the bleb, although in some individuals aqueous may not show this inhibitory effect on fibroblasts. ${ }^{15}$ The apparent difference between the lining of the tube tunnel and the fibrous tissue around the plate cavity might partly be due to the constituent materials in the implant (silicone rubber tube and polyacrylate), but the main reasons for the recognisable morphological differences is consistent with the effect of aqueous on fibroblasts observed in tissue culture. ${ }^{14}$

The focal choroiditis localised to the area beneath the implant plate may be another indication of the toxicity of aqueous under unphysiological conditions. This focal uveal inflammation might be mediated by products of the dying cells observed in the reactive fibrous tissue of the inner wall or perhaps by the aqueous itself reaching the choroid by diffusion across the sclera. The sclera, however, appeared unremarkable (Fig. 2g).

The Molteno implant is designed to utilise the outer wall of the plate cavity for the absorption of aqueous, but from our histological and electron microscopical findings it is evident that the lateral and the inner wall of the implant are equally involved. Indeed, no marked difference could be found either in collagen composition or cellular involvement in the tissue on either side of the plate, which lay loosely in its cavity. This indicates that the drainage area is much larger than the single surface previously described." The true surface area available for aqueous drainage extends on all surfaces of the plate. We therefore consider that for comparison with the absorptive area of other drainage devices the Molteno single plate should be attributed an area of $450 \mathrm{~mm}^{2}$. The presence of numerous episcleral vessels at the site of the implant points to a vascular component in the tissue reaction, since the equatorial episclera is relatively avascular under normal circumstances. ${ }^{17}$ The prominent gaps between the endothelial cells may indicate an increase in fluid exchange perhaps related to the direct biological effect of aqueous humour.

Further studies are required to investigate the effects of aqueous on the newly formed fibrous tissue and to elucidate its pathway into the vascular system, as this seems important in the maintenance of drainage in fistulising operations.

We thank Professor W R Lee for his valuable advice and encouragement and Mrs D Aitken for the electron microscopy.

\section{References}

1 Ellis R. Reduction of intraocular pressure using plastics in surgery. Am J Ophthalmol 1960; 50: 733-43.

2 Egerer I. Klinische Erfahrungen bei fistulierenden Glaukomoperationen mit Silikonkathetern. Klin Monatsbl Augenheilkd 1979; 174: 434-41.

3 Schocket SS, Lakhanpal V, Richards RD. Anterior chamber tube shunt to an encircling band in the treatment of neovascular glaucoma. Ophthalmology 1982; 89: 1188-94.

4 Kuljava Z, Ljubojeviv V, Momirov D. Draining implant for neovascular glaucoma. Am J Ophthalmol 1983; 96: 372-6.

5 Krupin T, Kaufman P, Mandell AI, et al. Long-term results of valve implants in filtering surgery for eyes with neovascular glaucoma. Am J Ophthalmol 1983; 95: 775-82.

6 Molteno ACB. New implant for drainage in glaucoma. Animal trial. Br J Ophthalmol 1969; 53: 161-8.

7 Molteno ACB. New implant for drainage in glaucoma. Clinical trial. Br J Ophthalmol 1969; 53: 606-15.

8 Molteno ACB, Van Rooyen MMB, Bartholomew RS. Implants for draining neovascular glaucoma. Br J Ophthalmol 1977; 71: $120-5$.

9 Ancker E, Molteno ACB. Die chirurgische Behandlung des chronischen Aphakieglaukoms mit dem Moltenokunststoffimplantat. Klin Monatsbl Augenheilkd 1980; 177: 365-70.

10 Brown RD, Cairns JE. Experience with the Molteno long tube implant. Trans Ophthalmol Soc UK 1983; 103: 297-311.

11 Ancker E, Molteno ACB. Molteno drainage implant for neovascular glaucoma. Trans Ophthalmol Soc UK 1982; 102: 122-4.

12 Cairns JE. The Molteno long-tube implant. Trans Ophthalmol Soc UK 1983; 103: 39-41.

13 Molteno ACB, Ancker E, Van Biljon G. Surgical technique for advanced juvenile glaucoma. Arch Ophthalmol 1984; 102: 51-7.

14 Kornblueth $\mathrm{W}$, Tenenbaum $\mathrm{E}$. The inhibitory effect of aqueous humor on the growth of cells in tissue cultures. Am J Ophthalmol $1956 ; 42: 70-4$.

15 Herschler T, Claflin A, Fiorentino G. The effect of aqueous humor on the growth of subconjunctival fibroblasts in tissue culture and its implications for glaucoma surgery. Am J Ophthalmol 1980; 89: 245-9.

16 Radius RL, Herschler T, Claflin A, Fiorentino G. Aqueous humor changes after experimental filtering surgery. Am J Ophthalmol 1980; 85: 250-4.

17 Hogan MJ, Alvarado JA, Weddell JE. Histology of the human eye. An atlas and textbook. Philadelphia, London, Toronto: Saunders, 1971: 192-3.

Accepted for publication 4 December 1986. 